\title{
Use and safety of KAATSU training: Results of a national survey
}

\author{
T. Nakajima, M. Kurano, H. lida, H. Takano, H. Oonuma, T. Morita, K. Meguro, Y. Sato, T. Nagata, \\ and KATTSU Training Group
}

Int. J. KAATSU Training Res. 2006; 2: 5-13

Correspondence to:

T. Nakajima, MD: Department of Ischemic Circulatory

Physiology, KAATSU Training,

University of Tokyo, 7-3-1

Hongo, Bunkyo-ku, Tokyo,

Japan 113-8655

masamasa@pb4.so-net.ne.jp

See end of article for authors' affiliations

\begin{abstract}
KAATSU training is a novel training, which is performed under conditions of restricted blood flow. It can induce a variety of beneficial effects such as increased muscle strength, and it has been adopted by a number of facilities in recent times. The purpose of the present study is to know the present state of KAATSU training in Japan and examine the incidence of adverse events in the field. The data were obtained from KAATSU leaders or instructors in a total of 105 out of 195 facilities where KAATSU training has been adopted. Based on survey results, 12,642 persons have received KAATSU training (male $45.4 \%$, female $54.6 \%$ ). KAATSU training has been applied to all generations of people including the young ( $<20$ years old) and the elderly ( $>80$ years old). The most popular purpose of KAATSU training is to strengthen muscle in athletes and to promote the health of subjects, including the elderly. It has been also applied to various kinds of physical conditions, cerebrovascular diseases, orthopedic diseases, obesity, cardiac diseases, neuromuscular diseases, diabetes, hypertension and respiratory diseases. In KAATSU training, various types of exercise modalities (physical exercise, walking, cycling, and weight training) are used. Most facilities have used 5-30 min KAATSU training each time, and performed it 1-3 times a week. Approximately $80 \%$ of the facilities are satisfied with the results of KAATSU training with only small numbers of complications reported. The incidence of side effects was as follows; venous thrombus $(0.055 \%)$, pulmonary embolism $(0.008 \%)$ and rhabdomyolysis $(0.008 \%)$. These results indicate that the KAATSU training is a safe and promising method for training athletes and healthy persons, and can also be applied to persons with various physical conditions.
\end{abstract}

Key words: KAATSU training; side effects; rehabilitation

\section{INTRODUCTION}

KAATSU training is a novel method for muscle training, originally developed by Sato (2005). Under the conditions of restricted muscle blood flow, even short-term, low-intensity exercise can induce muscle strength, and hypertrophy (Takarada et al, 2000b; Takarada et al., 2002; Takarada \& Ishii, 2002; Yasuda et al., 2004; Abe et al., 2005a, b). In addition, KAATSU training increases the amount of circulating growth hormone $(\mathrm{GH})$ (Takarada et al., 2000a; Takano et al., 2005a,b; Sato et al., 2005), which may enhance lipolysis and bone formation, resulting in a reduction of obesity and bone diseases as well as improving strength and inducing hypertrophy of muscle (Beekley et al., 2005). Also, GH stimulates the liver to secrete insulin-like growth factor-1 (IGF-1) (Abe et al., 2005a), which may improve the function of endothelium and insulin sensitivity. Thus, until now, KAATSU training has been widely used in healthy subjects and athletes, and has also been applied to various kinds of conditions such as orthopedic diseases, obesity and diabetes. However, the present state of KAATSU training remains unclear.

Apart from the beneficial effects of KAATSU training, the pressurization of blood vessels may cause the formation of thrombus, and induce microvascular occlusion (no-flow phenomenon) even after releasing blood flow restriction, resulting in muscle cell damage and necrosis (Harmon et al., 1948; Strock \& Majno, 1969; Kawada, 2005). Therefore, we are concerned about the formation of thrombus, muscle damage, and the occurrence of pulmonary embolism in the subjects, when KAATSU training is applied. In addition, although KAATSU training restricts venous flow, induces the pooling of venous blood, and subsequently reduces cardiac preload during exercise, which may be useful in rehabilitation in patients with cardiac diseases (Takano et al., 2005a, b; Iida et al., 2005), the excessive inhibition of cardiac preload may decrease cardiac output, and thereafter blood flow to the brain and coronary circulation. Consequently, side effects such as dizziness, fainting, cerebral anemia and the deterioration of ischemic heart disease may occur. But, detailed reports about the side effects of KAATSU training have not yet been reported. 
Therefore, to recognize the present state of KAATSU training and its side effects, we mailed questionnaires and obtained results from KAATSU leaders or instructors in a total of 105 facilities where KAATSU training has been adopted, and described them in this paper.

\section{METHODS}

\section{Subject}

Facilities where KAATSU training has been adopted participated in this study (see the appendix). We mailed questionnaire about KAATSU training to a total of 195 facilities in Japan, which had qualification of KAATSU leaders or instructors. The questionnaire asked about the distribution of age, training methods, training periods, side effects etc as described in Appendix 1.

\section{RESULTS}

We obtained an answer from KAATSU leaders or instructors in 105 out of 195 facilities (approximately $53 \%)$. As shown in Fig.lA, the number of bonesetter's and osteopath's offices and training gyms is larger than that of hospitals/clinics and rehabilitation centers.

Fig. 1B shows the period since the facilities have started KAATSU training. Most of the facilities (84\%) have started KAATSU training within 5 years. Until now, total 12,642 persons have been received it (male

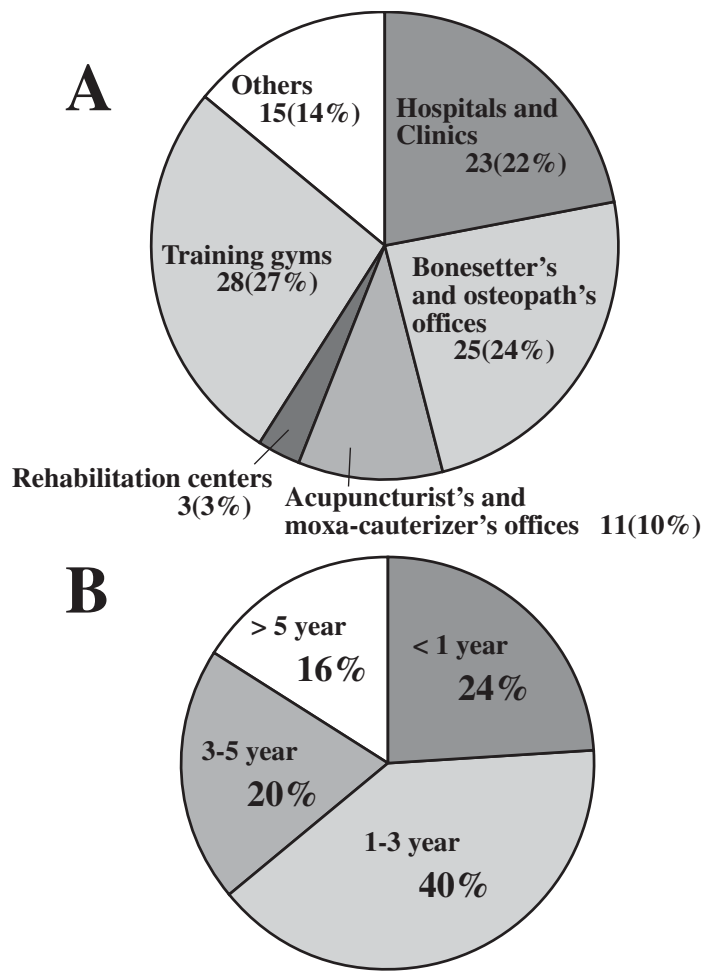

Figure 1. A: The kinds of the facilities $(n=105)$, who participated in this study. B: The distribution of the period since the facilities introduced KAATSU training.
$45.4 \%$, female $54.6 \%$ ).

Fig. 2 shows the age distribution of persons who have received KAATSU training in 105 facilities. The training was distributed over a wide range of ages. Persons aged under 20 years old accounted for $17.8 \%$, and persons aged over 70 years old accounted for $14.6 \%$ of the total. Thus, the KAATSU training appears to be widely applied to all ages.

Fig. 3 shows the number of the facilities classified by the object of the training (Fig. 3A) and the purpose of the use of KAATSU training with regard to

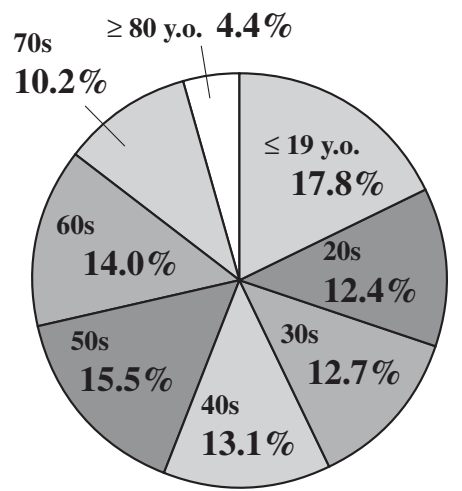

Figure 2. The age distribution of persons who have received KAATSU training in a total of 105 facilities.

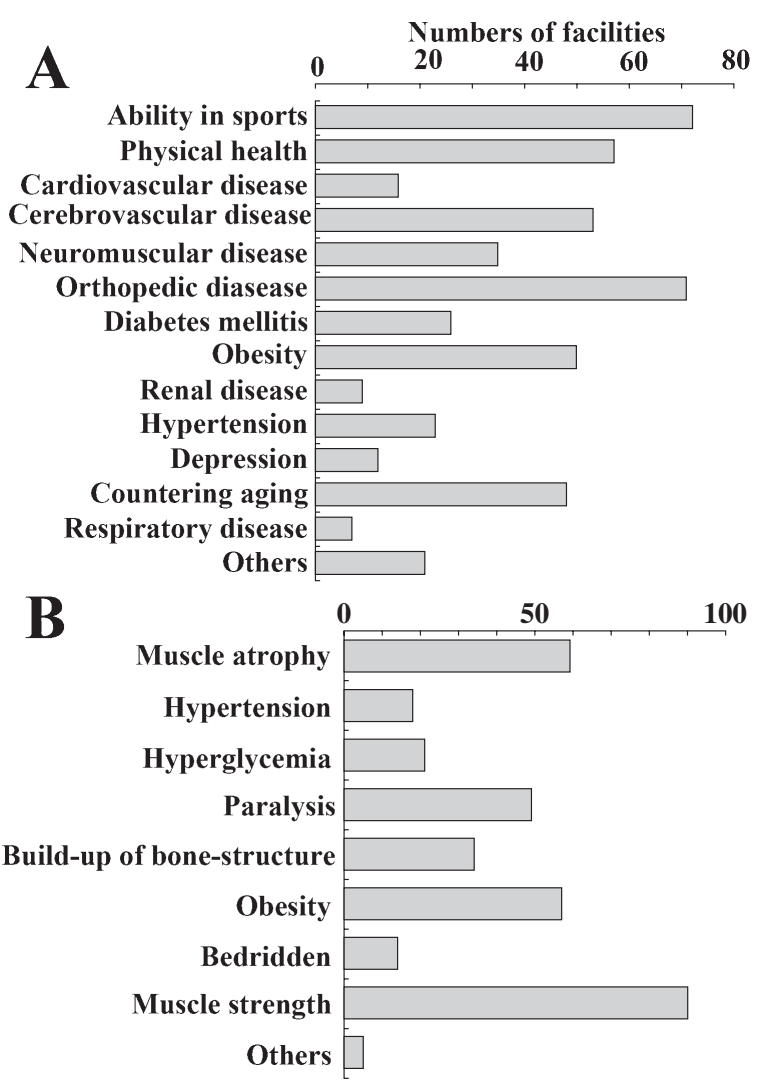

Figure 3. The object of the KAATSU training in each facility (A) and the symptom aimed to be improved with the use of KAATSU training (B). Numbers of facilities are indicated in each figure. 
symptoms (Fig. 3B). As illustrated in Fig. 3A, KAATSU training has been applied to various kinds of conditions; sports, healthy persons, cerebrovascular diseases, orthopedic diseases, obesity and countering aging. In addition, it has been also used for training patients with cardiac diseases, muscle diseases, diabetes, hypertension and respiratory diseases. Thus, KAATSU training is used for training persons with various kinds of physical conditions. The purpose of the use of KAATSU training by the various facilities was as follows (Fig. 3B); improvement of muscle strength or countering muscle atrophy, improvement of paralysis, build-up of bone-structure, reduction of obesity and prevention of old persons from becoming bedridden. Other purposes include improvement of the symptoms of Berger's disease, ateriosclerotic obliterans (ASO), bone atrophy, lumbago and shoulder stiffness, relief of pain including menstrual pain, countering aging, and maintenance of health.

The total number of persons per year who have received KAATSU training is shown in Fig. 4A. The annual number of visits to the facilities for KAATSU training was about 31,754 , and the mean annual

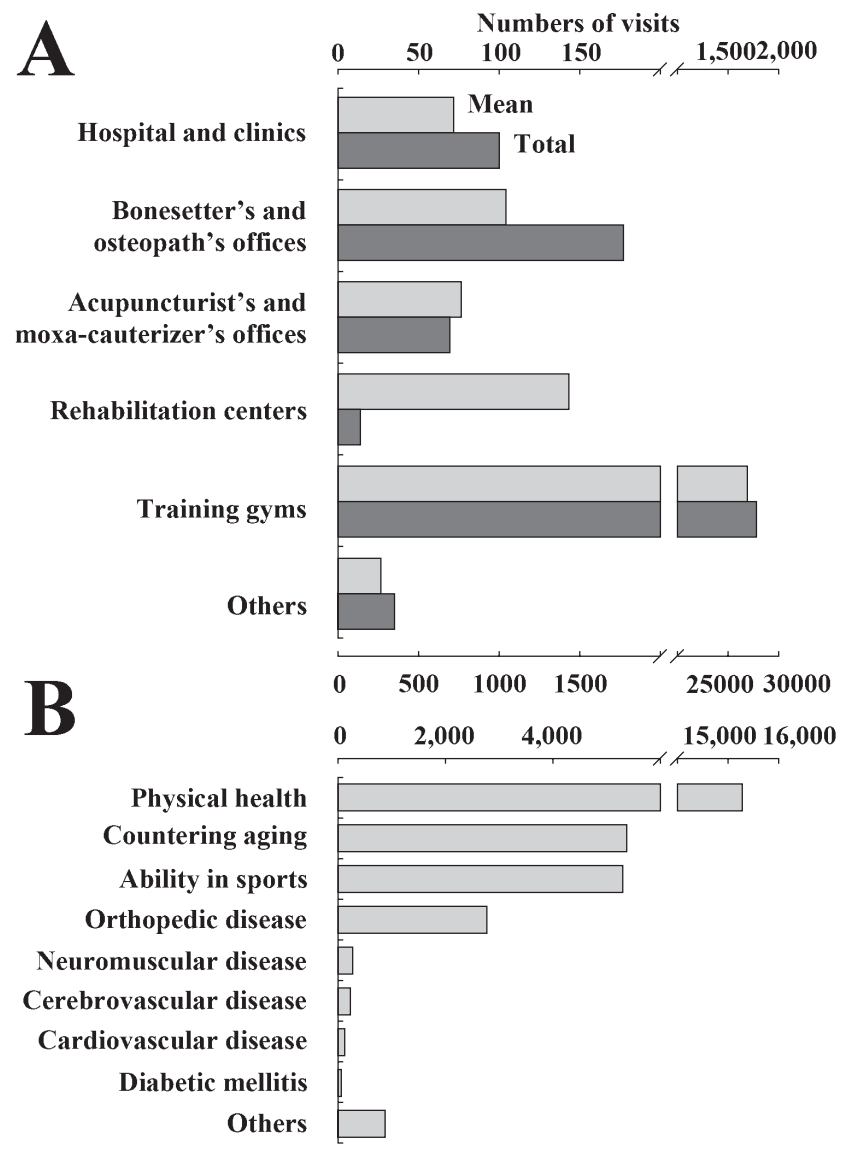

Figure 4. A: The annual number of visits in each type of facility. Mean numbers per facility and total numbers are indicated. B: The improvement with KAATSU training expected by subjects. Numbers of persons classified by expected improvement with KAATSU training are indicated. number of visits in one facility was 345 . KAATSU training has been applied to athletes $(n=5,311)$, orthopedic patients $(2,776)$, the elderly $(5,382)$ and healthy people $(15,284)$ as shown in Fig. 4B. Thus, KAATSU training has been mainly used for

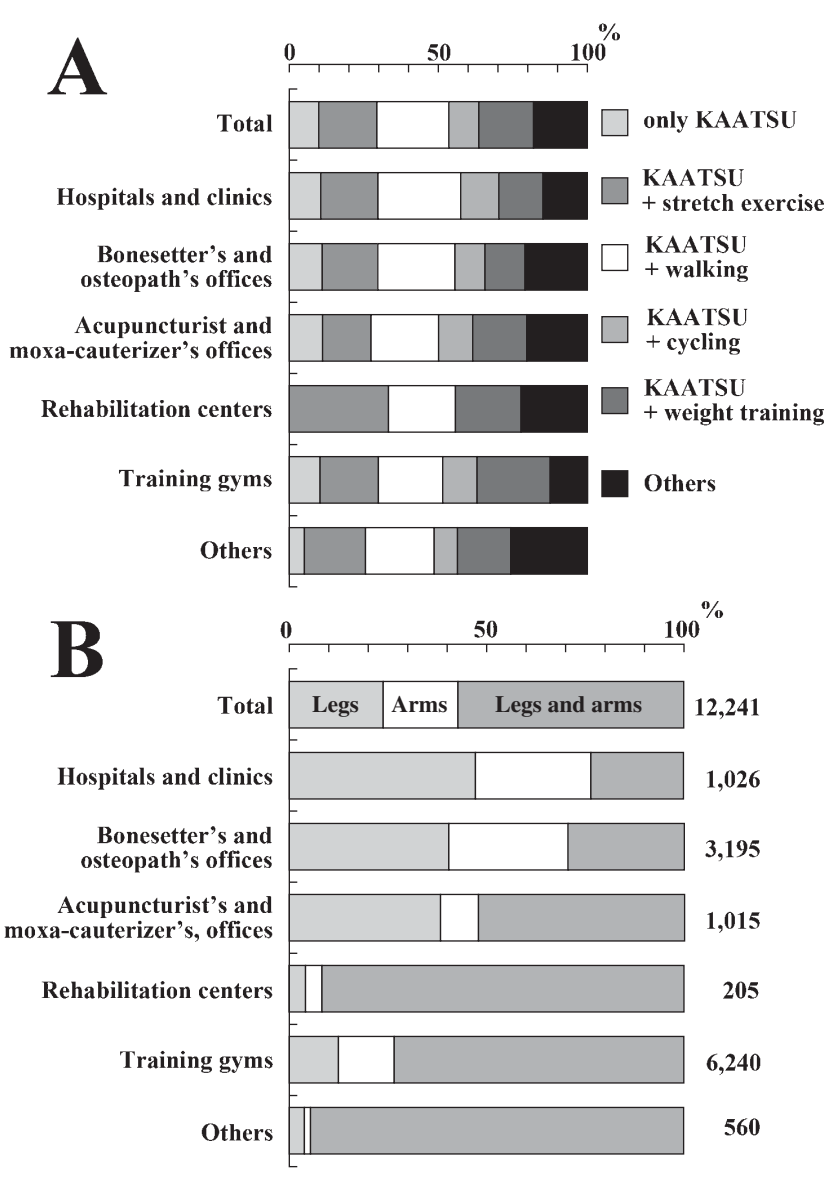

Figure 5. A: The distribution of type of exercises combined with KAATSU training in each type of facility. B: The distribution of part of body pressurized with KAATSU in each type of facility.

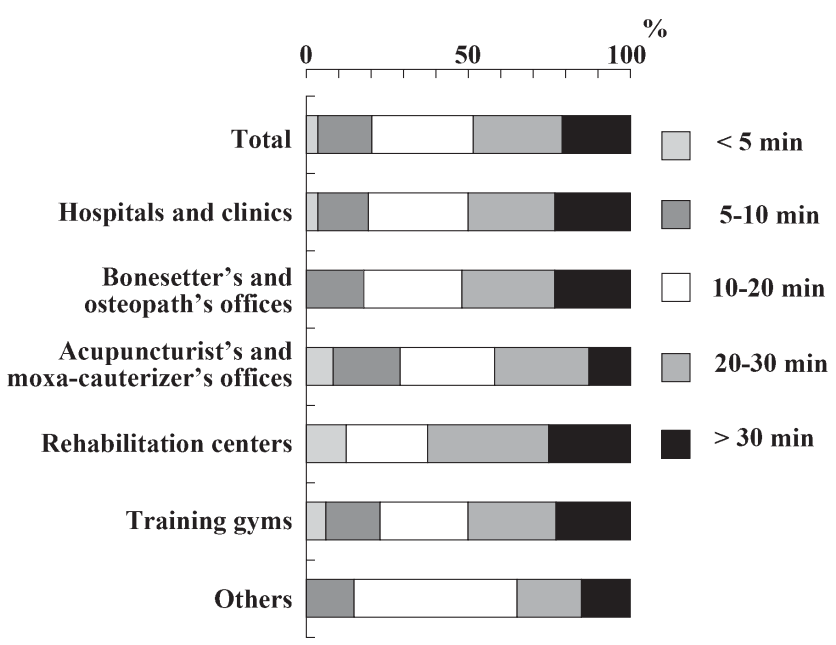

Figure 6. Training hours distribution of each KAATSU training. 

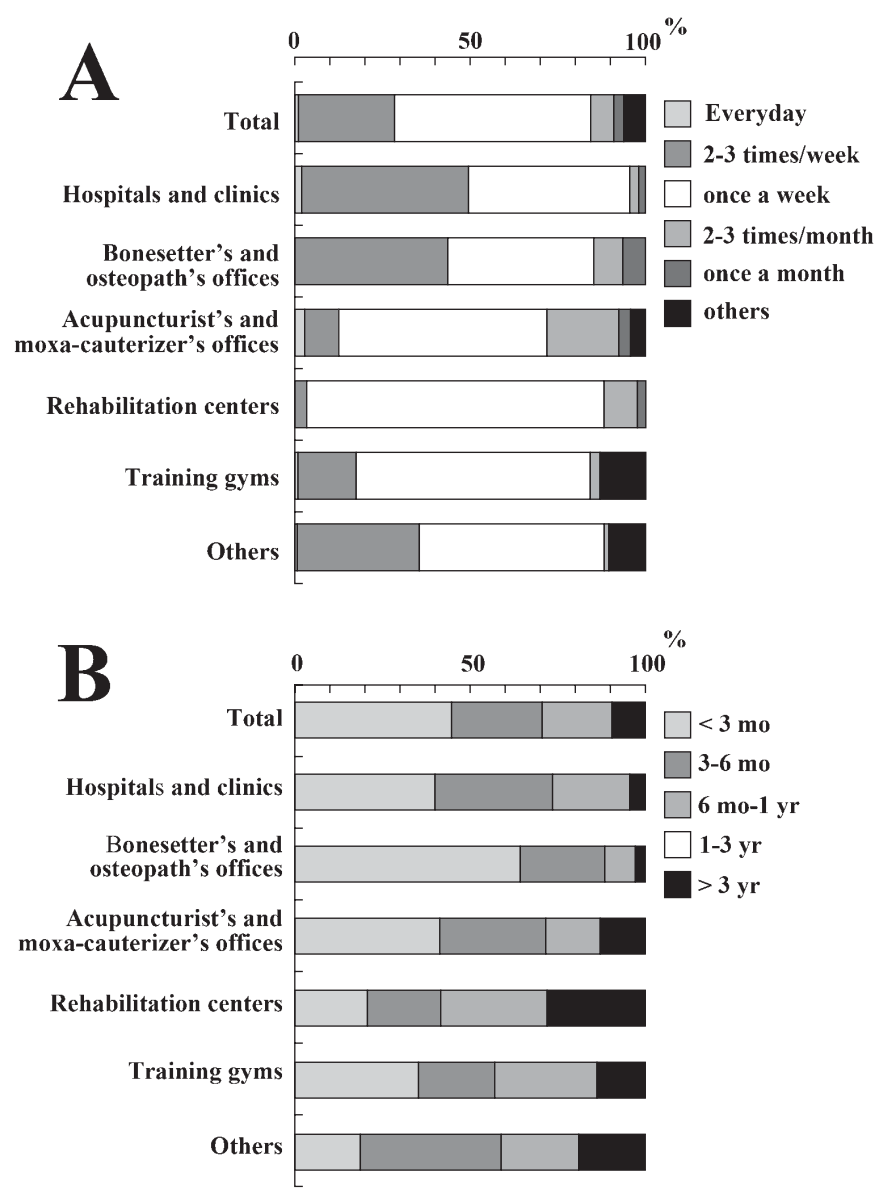

Figure 7. A: Frequency of KAATSU training in each type of facility. B: Period distribution of KAATSU training in each type of facility.

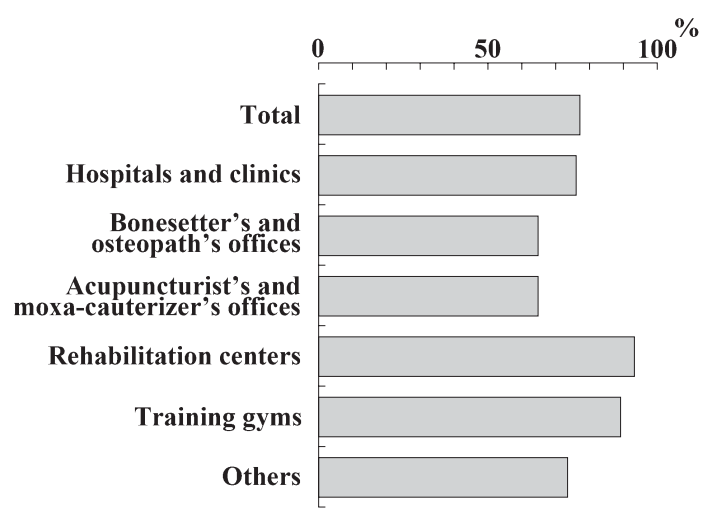

Figure 8. The proportion of facilities that were satisfied with the effect of KAATSU training.

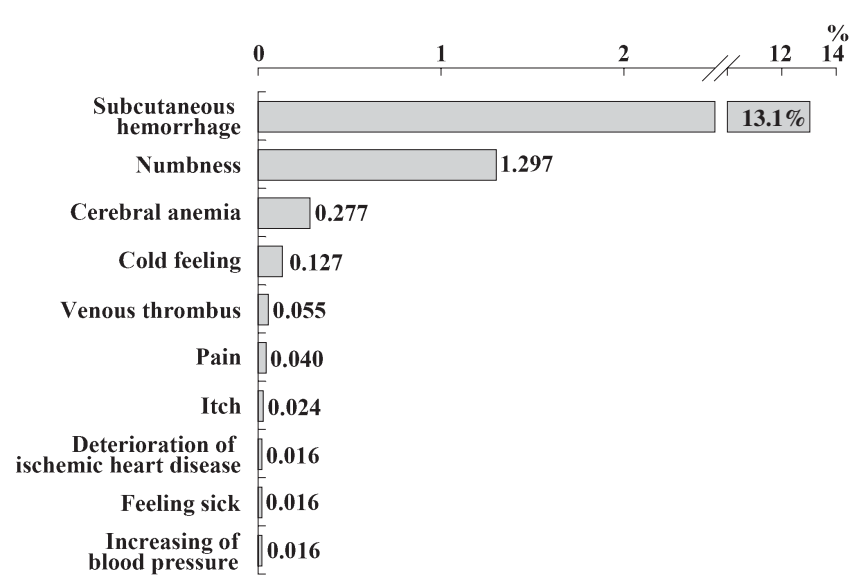

Figure 9. The most frequent side effects of KAATSU training.

Table 1. Side effects of KAATSU training and their occurrence in each type of facility.

\begin{tabular}{|c|c|c|c|c|c|c|c|}
\hline & Total & $\begin{array}{l}\text { Hospitals and } \\
\text { Clinics }\end{array}$ & $\begin{array}{c}\text { Bonesetter's and } \\
\text { osteopath's offices }\end{array}$ & $\begin{array}{l}\text { Acuouncturist's and } \\
\text { moxa-cauterizer's office }\end{array}$ & $\begin{array}{c}\text { Rehabilitation } \\
\text { centers }\end{array}$ & Training gyms & Others \\
\hline Subcutaneoushemorrhage & 1651 & 156 & 300 & 86 & 2 & 1105 & 2 \\
\hline Numbness & 164 & 6 & 67 & 42 & 1 & 48 & \\
\hline Cerebral anemia & 35 & 10 & 3 & 21 & & & 1 \\
\hline Coldfeeling & 16 & 2 & 10 & 1 & & 3 & \\
\hline Venousthrombus & 7 & 1 & 3 & 3 & & & \\
\hline Pain & 5 & 1 & 4 & & & & \\
\hline Itch & 3 & & & & & 3 & \\
\hline $\begin{array}{r}\text { Deteriorationofischemicheart } \\
\text { disease }\end{array}$ & 2 & & 2 & & & & \\
\hline Feeling sick & 2 & & 1 & & & 1 & \\
\hline Increasingofbloodpressure & 2 & & 1 & & & & 1 \\
\hline Physical weariness & 2 & & 1 & 1 & & & \\
\hline Dizziness & 2 & 2 & & & & & \\
\hline Pulmonaryembolism & 1 & & 1 & & & & \\
\hline Rhabdomyolysis & 1 & & 1 & & & & \\
\hline Palpitation & 1 & & 1 & & & & \\
\hline Nosebleed & & & 1 & & & & \\
\hline $\begin{array}{r}\text { Deteriorationofdiabetic } \\
\text { retinopathy }\end{array}$ & 1 & & 1 & & & & \\
\hline Fainting & 1 & & 1 & & & & \\
\hline Cerebral infarction & 1 & & 1 & & & & \\
\hline Hypoglycemia & 1 & 1 & & & & & \\
\hline Edema & 1 & 1 & & & & & \\
\hline Chafe & 1 & 1 & & & & & \\
\hline
\end{tabular}


strengthening of muscle in the field of sports, and health promotion in elderly and healthy subjects.

KAATSU training can be combined with various types of exercises. Fig. 5A shows types of exercises used with KAATSU training. As shown in Fig. 5A, it has been applied to stretch exercise, walking, cycling, and weight training. Many facilities have used both legs and arms as the sites of KAATSU (Fig. 5B). Figs. 6 and 7 show the percentage of the facilities classified by the training hours, frequency and duration of KAATSU training. Most of the facilities have been applying 5-30 min KAATSU training each time (Fig. 6), and have been doing it 1-3 times a week (Fig. 7A). In many cases, KAATSU training has been continued for at least 3-12 months as shown in Fig. 7B.

The reasons why subjects ended KAATSU training were as follows: improvement of their diseases or symptoms, achievement of goals, end of previously planned period, and shift to training at home. In 30 facilities, subjects have been continuing KAATSU training without stopping it. Fig. 8 shows the proportion of the facilities that are satisfied with the effects of KAATSU training (approximately 80\%).

Fig. 9 and table 1 summarize the side effects of KAATSU training. The occurrence ratio of side effects was as follows: subcutaneous hemorrhage $(13.1 \%)$, numbness $(1.297 \%)$, cerebral anemia $(0.277 \%)$, cold feeling $(0.127 \%)$, venous thrombus $(0.055 \%)$, pulmonary embolism $(0.008 \%)$, rhabdomyolysis $(0.008 \%)$, deterioration of ischemic heart disease $(0.016 \%)$ (Fig. 9 and table 1$)$. In addition, fainting has occurred in rare cases, and hypoglycemia has been reported.

\section{DISCUSSION}

The major findings of the present study obtained from 105 out of 195 facilities (approximately 53\%) are as follows: 1) KAATSU training has been used for a wide generation of people including the young (under 20 years old) and the elderly (over 80 years old), and has mainly been used for strengthening of muscle in the field of sports and health promotion in healthy subjects; 2 ) It has been also applied to various kinds of conditions; cerebrovascular diseases, orthopedic diseases, obesity, cardiac diseases, neuromuscular diseases, diabetes, hypertension, and respiratory diseases; 3 ) It can be combined with various types of exercises (e.g., walking, cycling, and weight training). In most of the facilities, subjects have received 5-30 min KAATSU training each time, 1-3 times a week; and 4) approximately $80 \%$ of the facilities are satisfied with the results of KAATSU training and there have been only a small number of side effects. Thus, KAATSU training is a safe and promising method of training not only for athletes, but also for ordinary people, and it can also be applied to persons with various physical conditions.
KAATSU training is a novel method for muscle training (Sato, 2005). Under conditions of restricted muscle blood flow, even short-term and low-intensity exercise can induce muscle strength and hypertrophy (Takarada et al, 2000b; Takarada et al., 2002; Takarada \& Ishii, 2002; Yasuda et al., 2004; Abe et al., 2005a, b). Therefore, as shown in the present study, many facilities have introduced KAATSU training for strengthening muscle in the fields of sports. The field of sports is indeed widespread, such as hockey, kendo, mountain climbin, jet skiing, triathlon, rugby, gymnastics, softball, handball, rock climbing, table tennis, badminton, marathon, skating, bicycle [cycle] race, skiing, snowboarding, bodybuilding, aerobics, judo, swimming, dance, basketball, tennis, volleyball, boxing, soccer, karate, golf, baseball, and combative sports. KAATSU training is also applied for health promotion in healthy subjects, even in the elderly. In addition, it has also been used to improve muscle strength in various conditions, including cerebrovascular diseases, respiratory diseases, orthopedic diseases, neuromuscular diseases, cases of being bedridden, and effects of old age.

Moreover, it is likely that KAATSU training is a useful method for training patients with a variety of diseases such as diabetes, hypertension and obesity. KAATSU training has additional effects, such as increasing GH secretion (Takarada et al., 2000a; Takano et al., 2005a, b; Sato et al., 2005). GH enhances lipolysis and bone formation, which may contribute to the reduction of obesity and bone diseases such as osteoporosis (Beekley et al., 2005). It also stimulates the liver to secrete insulin-like growth factor-1 (IGF-1) (Abe et al., 2005a), resulting in improvement of function of the endothelial cells and insulin sensitivity. Considering such effects of KAATSU training, some facilities have used KAATSU training for these patients.

In KAATSU training, various types of exercises can be used. In the present study, $30 \%$ of the facilities have used only KAATSU training. Even only KAATSU can prevent muscle atrophy observed in patients at bed rest (Takarada et al., 2000c). However, in most of facilities, various types of exercises (walking, cycling, and weight training) have been combined with KAATSU training. It is especially interesting to note that $70 \%$ of the facilities have used walking combined with KAATSU (commonly called "KAATSU walking"). Abe et al (2005b) reported that KAATSU walking can enhance GH responses, and then induce muscle strength and hypertrophy. In addition, no special machine is required in case of KAATSU walking. Therefore, KAATSU walking can be more widely adopted. Concerning duration and frequency, subjects have completed 5-30 min KAATSU training each time, 1-3 times a week in most of the facilities. However, since KAATSU 
training produces minimal muscle damage (Takarada et al., 2000a; Abe et al., 2005a), less recovery time is necessary, which means that the frequency of KAATSU training can therefore be increased according to the degree of its effect.

The most noteworthy finding is that the number of severe side effects due to KAATSU training is very low based on this survey results. The most frequent side effect was subcutaneous hemorrhage. It has been observed in $13.1 \%$ of cases, and more frequently occurred in arms than legs. However, subcutaneous hemorrhage is usually transient and diminished as the time goes on, even if training is continued. Therefore, subjects can continue the training with little cause for concern. Numbness has been observed in $1.297 \%$ persons who received KAATSU training, probably due to the compression of peripheral nerves of extremities. The numbness is also only temporary and abolished immediately after the release of KAATSU pressure. No cases of leg paralysis have occurred in any facility. Therefore, this symptom also does not interfere with KAATSU training. Several papers showed that KAATSU training combined with low-intensity exercise does not cause severe muscle injury, and there is no elevation of creatine phosphokinase (CPK) (Takarada et al., 2000a; Abe et al., 2005a) or rhabdomyolysis, as compared with heavy exercises (Chiu et al., 1976; Sorichter et al., 1999; Clarson \& Hubal, 2002). In fact, rhabdomyolysis was noted in only 1 case.

Occlusion of blood vessels sometimes causes the formation of thrombus, and induces microvascular occlusion (no-flow phenomenon) even after releasing blood flow restriction, resulting in muscle damage and cell necrosis (Harmon et al., 1948; Strock \& Majno, 1969; Kawada, 2005). However, fortunately, the incidence of serious side effects was low. Venous thrombus was observed in 7 cases $(0.055 \%)$. Pulmonary embolism was noted in only 1 case $(0.008 \%)$, but this subject had not been diagnosed definitely and had not serious problems. Recently, Tanimoto et al (2005) showed that the muscle oxygenation level during exercise with KAATSU training, measured with the near-infrared continuous-wave spectroscopy, was larger than that observed in completely-occluded conditions. Thus, it is likely that the blood flow is not completely restricted under the usual conditions with KAATSU exercise, which may help to avoid the severe side effects such as venous thrombus, pulmonary embolism and rhabdomyolysis.

Dizziness, fainting and cerebral anemia were observed in some cases as shown in table 2. Also, the deterioration of ischemic heart disease has been described in rare cases ( 2 cases). The conceivable reason is as follows; Application of KAATSU training on both legs caused the pooling of venous blood with the pressure-dependent reduction of femoral arterial blood flow (Iida et al., 2005). The inhibition of venous return during the KAATSU exercise reduces cardiac preload during the exercise, which may be beneficial in rehabilitation of certain patients with cardiac diseases (Takano et al., 2005a, b). On the other hand, the excessive inhibition of cardiac preload decreases cardiac output, and subsequently blood flow to the brain and coronary circulation. Therefore, KAATSU training should be performed carefully in patients with cardiac diseases such as ischemic heart diseases, severe aortic stenosis and hypertrophic obstructive cardiomyopathy. Also, the excessive application of KAATSU pressure may cause larger increases in both blood pressure and catecholamine levels as compared with low-intensity exercise without KAATSU training (Takano et al., 2005a, b). Therefore, we also need to be cautious when treating patients with hypertension and after cerebral hemorrhage as well as cardiac diseases. To minimize the side effects and complications, the KAATSU leaders and instructors should determine the duration and degree of KAATSU training as well as KAATSU pressure carefully. Of course, the informed consent about the side effects including subcutaneous hemorrhage should be given to all persons receiving KAATSU training. However, comparing with heavy physical exercises, where mortality rates of 0 to $2.5 \%$ per 10,000 have been reported, especially in older persons (ACSM, 2000; Kallinen M, 2005), any fatal complications have not been occurred in KAATSU training. Thus KATSU training is a safe and promising method for training persons including older persons.

In conclusion, KAATSU training is a safe and promising method for training in the field of sports and healthy persons, and can also be applied to persons with various kinds of physical condition including cerebrovascular diseases, orthopedic diseases, obesity, cardiac diseases, neuromuscular diseases, diabetes, hypertension, and respiratory diseases.

\section{ACKNOWLEDGEMENTS}

The assistance of Mr. Hiroyuki Imuta with manuscript preparation is greatly acknowledged. Mr. Y. Sato is a contributor of the department of KAATSU training, Ischemic Circulatory Physiology, University of Tokyo.

\footnotetext{
References

Abe T, Yasuda T, Midorikawa T, Sato Y, Kearns CF, Inoue K, Koizumi K, Ishii N (2005a) Skeletal muscle size and circulating IGF-1 are increased after two weeks of twice daily "KAATSU" resistance training. Int J KAATSU Training Res 1: 77-81.
}

Abe T, Kearns CF, Sato $Y(2005 b)$ Muscle size and strength are 
increased following walk training with restricted venous blood flow from the leg muscle, KAATSU-walk training. J Appl Physiol 100: 1460-1466 American College of Sports Medicine (ACSM) (2000) ACSM's guidelines for exercise testing and prescription. 6th edition. Lippincott Williams \& Wilkins, Philadelphia.

Beekley MD, Sato Y, Abe T (2005) KAATSU-walk training increases serum bone-specific alkaline phosphatase in young men. Int J KAATSU Training Res 1: 6-12.

Chiu D, Wang HH, Blumenthal MR (1976) Creatine phosphokinase release as a measure of tourniquet effect on skeletal muscle. Arch Surg 3: 71-74.

Clarson PM, Hubal MJ (2002) Exercise-induced muscle damage in humans. Am J Physiol Rehabil 231: E514-E520.

Harmon JW (1948) The significance of local vascular phenomena in production of ischemic necrosis in skeletal muscle. Am J Pathol 24: 625541.

lida H, Takano H, Meguro K, Asada K, Oonuma H, Morita T, Kurano M, Sakagami F, Uno K, Hirose K, Nagata T, Takenaka K, Suzuki J, Hirata Y, Furuichi T, Eto F, Nagai R, Sato Y, Nakajima T (2005) Hemodynamic and autonomic nervous responses to the restriction of femoral blood flow by KAATSU. Int J KAATSU Training Res 1: 57-64.

Kallinen M (2005) Cardiovascular benefits and potential hazards of physical exercise in elderly people. Journal of Sports Science and Medicine. 4 (Suppl.7): 1-51.

Kawada S (2005) What phenomena do occur in blood flow-restricted muscle? Int J KAATSU Training Res 1: 37-44.

Sato $Y$ (2005) The history and future of KAATSU training. Int J KAATSU Training Res 1: 1-5.

Sato Y, Yoshitomi A, Abe T (2005) Acute growth hormone response to low-intensity KAATSU resistance exercise: comparison between arm and leg. Int J KAATSU Training Res 1: 45-50.

Sorichter S, Pschendorf B, Mair J (1999) Skeletal muscle injury induced by eccentric muscle action: muscle proteins as markers of muscle fiber injury. Exerc Immunol Rev 5: 5-21.

Strock PE, Majno G (1969) Microvascular changes in acutely ischemic rat muscle. Surg Gynecol Obstet 129: 1213-1224.

Takano H, Morita T, lida H, Kato M, Uno K, Hirose K, Matsumoto A, Takenaka K, Hirata Y, Furuichi T, Eto F, Nagai R, Sato Y, Nakajima T (2005a) Effects of low-intensity "KAATSU" resistance exercise on hemodynamic and growth hormone responses. Int J KAATSU Training
Res 1: 13-18.

Takano H, Morita T, lida H, Asada K, Kato M, Uno K, Hirose K, Matsumoto A, Takenaka K, Hirata Y, Eto F, Nagai R, Sato Y, Nakajima T (2005b) Hemodynamic and hormonal responses to a short-term lowintensity resistance exercise with the reduction of muscle blood flow. Eur J Appl Physiol 95: 65-73.

Takarada Y, Nakamura Y, Aruga S, Onda T, Miyazaki S, Ishii N (2000a) Rapid increase in plasma growth hormone after low-intensity resistance exercise with vascular occlusion. J Appl Physiol 88: 61-65.

Takarada Y, Takazawa H, Sato Y, Takebayashi S, Tanaka Y, Ishii N (2000b) Effects of resistance exercise combined with moderate vascular occlusion on muscle function in humans. J Appl Physiol 88: 2097-2106.

Takarada Y, Takazawa H, Ishii N (2000c) Applications of vascular occlusion diminish disuse atrophy of knee extensor muscles. Med Sci Sports Exerc 32: 2035-2039.

Takarada Y, Sato Y, Ishii N (2002) Effects of resistance exercise combined with vascular occlusion on muscle function in athletes. Eur $\mathrm{J}$ Appl Physiol 86; 308-314.

Takarada Y, Ishii N (2002) Effects of low-intensity resistance exercise with short interest rest period on muscular function in middle-aaged women. J Strength Cond Res 16: 123-128.

Tanimoto M, Madarame H, Ishii N (2005) Muscle oxygenation and plasma growth hormone concentration during and after resistance exercise; comparison between "KAATSU" and other types of regimen. Int J KAATSU Training Res 1: 51-56.

Yasuda T, Abe T, Sato Y, Midorikawa T, Kearns CF, Inoue K, Ryushi T, Ishii N (2005) Muscle fiber cross-sectional area is increased after two weeks of twice daily KAATSU resistance training. Int J KAATSU Training Res 1: 65-70.

\section{Authors' affiliations}

T. Nakajima, M. Kurano, H. lida, H. Oonuma, Y. Sato, Department of Ischemic Circulatory Physiology, KAATSU Training, University of Tokyo, Tokyo, Japan

H. Takano, T. Morita, K. Meguro, Department of Cardiovascular Medicine, University of Tokyo, Tokyo, Japan

T. Nagata, Department of Respiratory Medicine, University of Tokyo, Tokyo, Japan

KATTSU Training Group, See the Appendix for a list of respondents. 


\section{Appendix 1. Questionnaire}

1 About your facility

1-1 What kind of facility is yours?
(1) Hospitals and Clinics
(2) Bonesetters' and osteopath's offices
(3) Acupuncturist's and moxa-cauterizer's offices
(4) Rehabilitation
(5) Training gyms
(6) Others

1-2 When did your facility introduce KAATSU training?
(1) < 1 year ago
(2) $1 \sim 3$ years ago
(3) $3 \sim 5$ years ago
(4) $>5$ years ago

$1-3$

(1) How many KAATSU leaders does your facility have? persons

(2) How many KAATSU instructors does your facility have? persons

2 About your cases or patients

2-1 How is the distribution of age of your subjects who have ever taken KAATSU training in your facility?
$<19$ years
$20 \sim 30$ years
persons
$30 \sim 40$ years
persons
$40 \sim 50$ years
persons
$50 \sim 60$ years
persons
$60 \sim 70$ years
persons
$70 \sim 80$ years
persons
$>80$ years
persons

2-2 How is the proportion of sex $(\%)$ in your facility?

$$
\text { Male } \quad \%
$$

Female

2-3 What is the object of KAATSU training in your facility?

Training or health promotion
(1) Athletes
(2) Astronauts
(3) Ordinary healthy persons

Rehabilitation or prevention
(1) Cardiovascular disease
(2) Cerebrovascular disease
(3) Neuromuscular disease
(4) Orthopedic disease
(5) Diabetes mellitus
(6) Obesity
(7) Renal disease (including hemodialysis)
(8) Hypertension
(9) Depression
(10) The elderly
(11) Respiratory disease
(12) Others ( )

2-4 What is the symptom aimed to be improved with the use of

KAATSU training?
(1) Muscle atrophy
(2) Hypertension
(3) Diabetes mellitus
(4) Paralysis
(5) Bone disease (build-up of bone-structure)
(6) Obesity
(7) Bedridden
(8) Increase of muscle strength
(9) No particular symptom
(10) Others ( )

2-5 How many visits are there in your facility a year?

3 About KAATSU training

3-1 What types of exercises are combined with KAATSU training?

(1) Only KAATSU

(2) Physical exercise

(3) Walking (including treadmill)

(4) Cycling

(5) Weight training

(6) Others (

3-2 What parts of subject's body do you apply KAATSU training?

Legs: persons

Arms: persons

Both legs and arms: persons

3-3 How often do your subjects visit your facility?
(1) Everyday
(2) 2-3 times a week
(3) Once a week
(4) 2-3 times a month
(5) Once a month
(6) Others ( )

3-4 How is the distribution of the duration to treat each subject in your facility?
(1) $<3$ months
(2) 3-6 months
(3) 6 months - 1 year
(4) 1-3 years
(5) $>3$ years

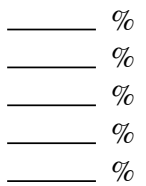

3-5 How long is each training period in your facility?
(1) $<5$ minutes
(2) 5-10 minutes
(3) 10-20 minutes
(4) 20-30 minutes
(5) $>30$ minutes

4 About effect of KAATSU training

4-1 How large is the proportion of your subjects who is satisfied with the effect of KAATSU training? $\%$

4-2 How many subjects have suffered from the side effect of KAATSU training? persons

4-3 What is the side effect of KAATSU training that your subjects suffered from?

(1) Cold feeling

(2) Numbness

(3) Subcutaneous hemorrhage

(4) Venous thrombus

(5) Pulmonary embolism

(6) Rhabdomyolysis

(7) Myocardial infarction

(8) Others (

4-4 To what point do you pay attention while you treat your subjects? persons 


\section{Appendix 2}

List of Respondents; Denenchofu-iin (clinic), Kohno Internal medicine clinic (clinic), Kamo hospital (hospital), Tokuyama-seikeigeka (orthopedic clinic), Kurihara seikeigeka (orthopedic clinic), Endo Kikyo Children's clinic (clinic), Konfogarden clinic (clinic), Ikujinkai Medical Corporation of Odagiri hospital (hospital), Social Insurance Shiga Hospital (hospital), Inove hospital/clinic (hospital and clinic), Keiyu-seikeigeka (orthopedic hospital), Fukuda-seikeigeka (orthopedic clinic), Sata-seikeigeka hospital (hospital), Medical corporation Koueikai Inove Orthopedic Surgery Clinic (clinic), Department of Ischemic Circulatory Physiology, KAATSU Training, University of Tokyo (hospital), Takeuchi-seikotsuin (osteopath's office), Synthetic Therapy \& Conditioning Plaza (osteopath's and acupuncturist's office), Yoshimura-sekkotsuin/Kenshin-club (bonesetter's office), Yomeido Acupuncture \& judo therapist clinic (osteopath's office), Kobayashi-seikotsuin (osteopath's office), WAKABA SEKKOTUIN (bonesetter's office), Nishiodo seikotuin (osteopath's office), Itosekkotsuin (bonesetter's office), Kusaka bonesetting office (bonesetter's office), Kuga bonesetter's office (bonesetter's office), Nemoto-sekkotsuin (bonesetter's office), Tanaka-seikotsuin (osteopath's office), EkakuMizuno-seikotsuin (osteopath's office), Koga JUDO Therapy Office (osteopath's office), ARISAWA BONESETTER (bonesetter's office), Hayashi-sekkotsuin (bonesetter's office), GOKISO SEKKOTSUIN (bonesetter's office), Kanai-sekkotsuin (bonesetter's office), KOMATA BONESETTER'S OFFICE (bonesetter's office), Mizuno-sekkotsuin (bonesetter's office), Shonan-sekkotsuin (bonesetter's office), Magaribuchi Judo Therapy Centre, Yuri-seikotsuin (osteopath's office), KINOSITA SEIKOTUIN (osteopath's office), Mori-Shuichi-seikotsuin (osteopath's office), A spin treatment House (acupuncturist's and moxacauterizer's office), Athlete support/KAATSU training Toshima-branch (acupuncturist's and moxa-cauterizer's office), YUWA-acupuncture (acupuncturist's and moxa-cauterizer's office), Taiyo-shinkyuin/KAATSU training Fukui school (acupuncturist's and moxa-cauterizer's office), FURUYA ACUPUNCTURE (acupuncturist's and moxa-cauterizer's office), First step (acupuncturist's and moxa-cauterizer's office), TOKOROZAWA
SPORTS CARE CENTER (acupuncturist's and moxa-cauterizer's office), RITTAI CHIROPRACTIC (acupuncturist's and moxa-cauterizer's office), MAEDA CHINESE MEDICAL/KAATSU training Osaka-Daito-shi-branch (acupuncturist's and moxa-cauterizer's office), Roppongi conditioning (acupuncturist's and moxa-cauterizer's office), Osaka-sakai-chiropractic (acupuncturist's and moxa-cauterizer's office), Inove-conditioning (rehabilitation center), Armring Physical Plaza (rehabilitation center), Training center SUNPLAY (training gym), Maruyu-training-center (training gym), KAATSU-sports-seitai-seikotsusho (training gym), ATLAS (training gym), DO SPORTS. PLAZA (training gym), Training-collegeKubira (training gym), BODYCRAFT Sports Conditioning HIRATSUKA (training gym), KAATSU training Yotsukaichi-branch (training gym), Fitness-care-Hokuetsu (training gym), Asahi KAATSU Training Studio (training gym), Hoasen Sports Plaza (training gym), Able-fitness-clubOkayama (training gym), Asurie-sekkotsuin/Asurie-sports-club (training gym), GOLF \& FITNESS CLUB S.I.H (training gym), Maruya-gym (training gym), TOTAL conditioning (training gym), KAATSU training Kiryu-branch (training gym), K Medical Training Center (training gym), KENKO PLAZA SKIP (training gym), Shinkyuin-Gen/TRAINING GYM Genkijuku (training gym), TAIL TOP (training gym), Conditioning \& Cure support (training gym), B-sports (training gym), SPORTS CLUB NAS, ROX (training gym), Conditioning Club P.C.P (training gym), TIPNESS, TOKYU SPORTS OASIS (training gym), SPORTS GYM COSMOS Åitraining gym), Arugo Sports Service CO. Ltd. (training gym), Sato sports plaza, Taro Ikezaki, Niigata university, KAATSU training KobeNishi-ku-branch, KAATSU training Tomakomai-branch, KAATSU training Okinawa-branch (Ryukyu university), KAATSU training Muroran-branch /Kyokushin-kaikan Hokkaido-Kimohuri-branch, Genkisports, Satoshi Tanabe, KAATSU training Oita-branch, KAATSU training Kashiwa-branch, Orange garden, SAGINUMA SWIMMING CLUB, AVISPA FUKUOKA, Noriko Konuma, SPORTS SHOP XEBIO DOME SAPPORO, KAATSU training Takasaki-branch (Miho Harada), and others. 